\title{
Design of Social Responsibility Incentive Contracts for Stakeholders of Megaprojects under Information Asymmetry
}

\author{
Feng Xue ${ }^{1, *}$, Guangyu Chen ${ }^{1} \mathbb{D}$, Shanming Huang ${ }^{1}$ and Huan $\mathrm{Xie}^{2}$ \\ 1 School of Management and Economics, University of Electronic Science and Technology of China, \\ Chengdu 611731, China; chenguangyu@uestc.edu.cn (G.C.); hsm@uestc.edu.cn (S.H.) \\ 2 Sichuan Provincial Branch of Southwest Regional Headquarters, China Communications Construction \\ Company Ltd., Chengdu 610218, China; huanx1999@163.com \\ * Correspondence: xuefeng841116@163.com
}

check for

updates

Citation: Xue, F.; Chen, G.; Huang, S.; Xie, H. Design of Social Responsibility Incentive Contracts for Stakeholders of Megaprojects under Information Asymmetry. Sustainability 2022, 14, 1465. https://doi.org/10.3390/ su14031465

Academic Editors: Pierfrancesco De Paola, Francesco Tajani, Marco Locurcio and Felicia Di Liddo

Received: 29 December 2021

Accepted: 25 January 2022

Published: 27 January 2022

Publisher's Note: MDPI stays neutral with regard to jurisdictional claims in published maps and institutional affiliations.

Copyright: () 2022 by the authors Licensee MDPI, Basel, Switzerland. This article is an open access article distributed under the terms and conditions of the Creative Commons Attribution (CC BY) license (https:/ / creativecommons.org/licenses/by/ $4.0 /)$.

\begin{abstract}
Social responsibility is essential to the sustainable development of megaprojects. A transparent and symmetrical information-sharing mechanism is an important guarantee for promoting megaproject stakeholders to fulfill their social responsibilities and improve project efficiency. Aiming at the problems of megaproject subcontractors concealing social responsibility information, which leads to unsmooth information channels and low project efficiency, this paper compares and analyzes the single-stage revenue-sharing model under symmetric and asymmetric information from the perspective of incentive contract design. Then, a two-stage incentive contract with multiple indicators under asymmetric information is designed using principal-agent theory. The research results show that the social responsibility effort level of the general contractor and the total project revenue is positively correlated with the input-output ratio, and is negatively correlated with the degree of information opacity of the subcontractor's social responsibility. Incentive contracts with multiple indicators in stages can effectively encourage subcontractors to disclose social responsibility information, and reduce information asymmetry, therefore enhancing social responsibility and improving overall project efficiency. This research transforms the research on the social responsibility of megaprojects from qualitative to quantitative. The research results provide theoretical methods and decision-making basis for megaproject general contractors to encourage subcontractors to improve social responsibility.
\end{abstract}

Keywords: megaproject; social responsibility; stakeholder; moral hazard; information asymmetry; incentive mechanism

\section{Introduction}

In the context of the Belt and Road Initiative and the national strategy for sustainable development, China's major infrastructure projects (hereinafter referred to as megaprojects) are facing an unprecedented environmental sensitivity period, strategic opportunity period, and value reconstruction period. Therefore, in addition to paying attention to the progress, cost, and quality of the projects themselves, the stakeholders of megaprojects should also focus on project social responsibilities such as avoiding harm to public safety, maintaining ecological balance, and achieving sustainable development [1]. In reality, some project stakeholders excessively pursue their economic interests while neglecting social responsibilities, leading to frequent accidents. In 2013, the collapse of the Sava District Building in Bangladesh, which killed 1127 people, shocked the world. The main reason was the owners' lack of a strict review mechanism, and the project was multi-level contracted. Subcontractors cut corners and built-in violation of regulations; government departments had information asymmetry in those mentioned above lacking social responsibility behaviors, leading to government supervision and management dereliction, which eventually led to tragic accidents [2]. Even the consequences of general projects due to the lack of social responsibility are such serious, to say nothing of the megaproject. For megaprojects, the 
construction period is exceptionally long, the relationship is intricate, supervision is more difficult, and information asymmetry is more serious than ordinary engineering. Slight negligence of project stakeholders in the process of decision-making and implementation may lead to consequences beyond the project itself, which may evolve into a series of serious social problems, seriously restricting the sustainable development of megaprojects and the economy and society. Therefore, studying the social responsibility management of megaprojects under asymmetric information has important practical significance.

The social responsibility of megaprojects refers to the policies and practices adopted by megaproject stakeholders to fulfill their responsibilities for achieving broader social well-being during the entire lifecycle of the project [3]. Compared with general projects, megaprojects mainly have the following differences. (1) Project stakeholders must assume social responsibility [4]. General projects only need to carry out project construction following the contract (time, cost, quality, etc.), and there is no mandatory constraint on social responsibility. The megaprojects have far-reaching and irreversible impacts on environmental changes, economic development, and social progress. Therefore, stakeholders at all stages of the lifecycle of megaprojects must consider social responsibilities to ensure the sustainability of megaprojects. For example, the Hong Kong-Zhuhai-Macao Bridge project, while ensuring the quality of the project, is also required to take the social responsibility of long and durable design, green and low-carbon construction, and low-emission and low-consumption operation [5]. (2) Information asymmetry is more serious [6]. For megaprojects, the long construction period, complicated relationships, imperfect supervision system, and difficult identification of social responsibility efforts have caused serious information asymmetry. Moreover, megaprojects often adopt the general contracting model, i.e., the government (owner) is only responsible for overall management and control, and only signs general contracting contracts with the general contractor. The general contractor is responsible for all the work of the subcontractors to the owner [7]. Therefore, subcontractors have a weak sense of responsibility compared with the owner and contractor, and there are double opportunistic behaviors of moral hazard and adverse selection, which can easily induce project accidents.

In view of the two characteristics of social responsibility for megaprojects, serious information asymmetry will lead to opportunistic behavior and inhibit other stakeholders from promoting social responsibility. Therefore, this paper intends to encourage project stakeholders to disclose responsibility information and enhance social responsibility through contract design. In practice, the construction stage is the most important stage in the lifecycle of megaprojects, and it is also the stage most prone to accidents and hidden dangers. The main stakeholders at this stage include the owner (government), general contractors, and subcontractors. Therefore, studying the social responsibility incentive mechanism of the main stakeholders in the construction stage is of great significance to promote the project's success and reduce the project risk. In summary, this paper intends to study the following two issues. (1) Based on the perspective of the general contractor, we investigate how to design an incentive contract to solve the dual problems of adverse selection and moral hazard caused by subcontractor information asymmetry. (2) Based on the incentive contract model, we study the relationship and influencing factors of the social responsibility effort level, the revenue distribution ratio, and the total project revenue of the general contractor and subcontractors.

\section{Literature Review}

The social responsibility of megaprojects is the common responsibility of all stakeholders, and each stakeholder is part of the responsibility chain. This mainly includes economic responsibility, legal responsibility, ethical responsibility, and political responsibility [8]. Among them, the government's social responsibility (owner) is mainly reflected in realizing the value of the project, paying attention to public needs, formulating laws and regulations, and maintaining social stability. The general contractor's social responsibility is mainly reflected in ensuring quality and safety, controlling construction period and cost, innovating 
technology and process, optimizing resources and allocation, and coordinating interests and conflicts. The subcontractor's social responsibility is mainly reflected in the use and promotion of green materials, paying attention to employees' occupational health, and the protection of the construction site environment [9]. In the whole lifecycle of a megaproject, the social responsibilities of stakeholders are heterogeneous and interactive, and the highly integrated governance of government, enterprises, and the public can promote the creation of sustainable value of megaprojects [10]. The social responsibility of megaprojects has aroused great attention in academic circles, and many scholars have studied it from different perspectives. On the one hand, according to the characteristics of social responsibility of the megaproject, some scholars have constructed an indicator evaluation system of social responsibility of megaprojects [11,12]. On the other hand, some scholars have evaluated and analyzed the social responsibility risks of megaprojects based on social network analysis $[13,14]$. Moreover, some scholars have studied the relationship between the social responsibility of megaprojects and project efficiency and sustainability $[9,15]$. In summary, the existing research on the social responsibility of the megaprojects mostly focus on constructing the conceptual framework of social responsibility, establishing an indicator evaluation system, and sustainable development [14,15]. Few studies focus on social responsibility incentives for project stakeholders.

Megaproject features are high complexity, numerous stakeholders, and imperfect supervision systems, which have caused serious information asymmetry among project stakeholders, led to the double opportunistic behaviors of moral hazard and adverse selection of some stakeholders, and severely restricted the smooth implementation of the project and sustainable development $[16,17]$. Sheng et al. suggest that one of the issues of megaproject decision-making governance is to conduct an in-depth study on the process of megaproject decision-making governance to deal with adverse selection and other moral hazard issues [18]. Xiang et al. studied the probability and impact of information asymmetry among owners, contractors, and supervisors, and pointed out that opportunistic behavior caused by information asymmetry is the main cause of project loss and risk [19]. In the entire lifecycle of megaprojects, subcontractors are likely to cause double information asymmetry problems in the construction stage due to their weak sense of responsibility [20]. The study of pure moral hazard assumes that the agent's actions are not visible to the principal [21]. After Holmstrom proposed a general framework [22], many scholars have further developed it and applied it to different industries [23]. Based on PPP projects, Paez-Perez and Sanchez-Silva discussed a dynamic principal-agent model to solve the moral hazard problem caused by project information asymmetry [24]. The study of pure adverse selection assumes that the agent has some private information that is not visible to the principal $[25,26]$. Aiming at the adverse selection problem in the megaprojects' BOT model, Shi designed contracts to encourage companies to report information truthfully, therefore improving the BOT project's optimal capacity ratio [27]. The above studies provide ideas and methods for this research, but currently, few studies simultaneously study information asymmetry with the coexistence of moral hazard and adverse selection in the field of engineering.

A reasonable incentive mechanism plays a vital role in the construction of megaprojects. Qi et al. proposed that contract incentives, supplier selection, and collaborative cooperation play a positive role in constructing megaprojects' factories [28]. Shi et al. proposed that in the design of megaproject incentive mechanisms, stakeholders not only pay attention to revenue but also pay attention to reputation. A reasonable incentive model can encourage stakeholders to improve their effort level [29]. Through model analysis, Qiu et al. concluded that effective government supervision and incentive mechanisms could significantly improve the effort level of the construction entity and the overall benefits of the project, and the greater the supervision and incentive level, the harder the construction entity will work [30]. In the field of megaprojects, there are few studies on the promotion of social responsibility through the design of incentive mechanisms, and most of them are concentrated in the field of supply chain [31], such as revenue-sharing contracts [32], 
wholesale contracts [33], cost-sharing contracts [34], and multiple contract comparison [35]. These studies show that in the field of the supply chain, a reasonable social responsibility incentive mechanism can increase consumers' desire to purchase and consumption demand, therefore further increasing the revenue of supply chain members. The purpose of megaprojects to enhance social responsibility is to avoid later project risks, social conflicts, and hidden safety hazards. Therefore, to study the social responsibility of stakeholders in megaprojects, we should not only consider the revenues of stakeholders but also consider the overall benefits of megaprojects.

The existing research achievements provide ideas for further research on the social responsibility of stakeholders in megaprojects. However, through literature review, it is found that the current research on the social responsibility of megaprojects is mostly based on qualitative aspects, such as the establishment of a conceptual framework for social responsibility, the establishment of an indicator evaluation system, and the impact of sustainable development. By comparison, there is rare research carried out from a quantitative perspective. Therefore, this paper starts from the perspective of incentive contract design, combines the characteristics of megaproject social responsibility, and aims at the bilateral problems of moral hazard and adverse selection caused by subcontractor information asymmetry, uses principal-agent theory to design a two-stage incentive contract, and compares it with the single-stage revenue-sharing model. It is concluded that the two-stage incentive contract can significantly improve the social responsibility effort level of the subcontractor and the total project revenue. The research results provide theoretical methods and decision-making basis for general contractors of megaprojects to encourage subcontractors to improve social responsibility.

Compared with existing research, the main features of this paper are as follows: (1) to quantitatively study the information disclosure mechanism and influencing factors of megaproject subcontractors from the perspective of incentive contract design; (2) to design a multi-indicator two-stage incentive contract to address the dual information asymmetry problem of subcontractors' moral hazard and adverse selection; and (3) to prove that the multi-indicator two-stage incentive contract is more effective than the single-stage revenue-sharing model.

\section{Single-Stage Revenue-Sharing Model}

\subsection{Problem Description and Model Assumptions}

(1) Although there is more than one subcontractor during the design and construction of megaprojects, the nature and objectives of these subcontractors are similar, all for assisting the general contractor to complete the project objectives with high quality. Therefore, the decision-making body of this paper is the owner (government), a general contractor, and a subcontractor.

(2) The general contracting mode is a modern project management mode commonly used in megaprojects. The government (owner) is only responsible for overall management and control, and only signs general contracting contracts with general contractors. The form of the contract is a linear contract with a fixed total price plus bonus [36], i.e., $W=\bar{\omega}+\lambda M$, where $W$ is the total contract price, and $\bar{\omega}$ is the fixed total price obtained after the general contractor reaches the lowest quality, construction period, and cost standards, and $\lambda M$ is an incentive bonus given by the owner to encourage the general contractor to make contributions to social responsibilities such as technological innovation, rational use of resources, and protection of the ecological environment. $\lambda$ $(0<\lambda<1)$ is the incentive coefficient, and $M$ is the total output of the cooperative cooperation between the general contractor and the subcontractor.

(3) Megaprojects are highly complex, especially for the "bottleneck problem". The general contractor needs to select some outstanding subcontractors to coordinate and cooperate to complete the project's tasks. To encourage subcontractors to improve their social responsibilities, the general contractor signs a fixed total price plus bonus contract with the subcontractors. The form of the contract is $P=\bar{p}+(1-\beta) \lambda M$, 
where $P$ is the total contract price given by the general contractor to the subcontractor, $\bar{p}$ is the fixed total price obtained by the subcontractor completing the subcontracting project in accordance with the minimum requirements, $(1-\beta) \lambda M$ is the subcontractor's received incentive bonuses due to its contribution to the social responsibility of construction environmental protection, construction quality assurance, and promotion of green materials, etc. $\beta$ and $1-\beta(0<\beta<1)$ are the revenue distribution ratios of the general contractor and the subcontractor after receiving the owner's reward.

(4) Megaprojects, as a complex and huge system with far-reaching influence, not only need the general contractor and subcontractor to always pay attention to social responsibility, but also need their cooperation and joint efforts to overcome difficulties and promote sustainable development of the project. There are two common models in supply chain research to depict social responsibility. One is that social responsibility directly affects the demand function of products in a linear manner [37,38]. The other is that social responsibility is embedded in the consumer surplus function and indirectly affects demand [33,39]. The social responsibility of the megaproject is different from corporate social responsibility. Its demand for the quantity of product is determined and will not be affected by social responsibility. The social responsibility of stakeholders in the megaprojects mainly affects project output performance and project sustainability $[3,15]$. Based on empirical studies, He et al. and Ma et al. have concluded that the social responsibility of megaproject stakeholders has a direct and significant positive impact on project output performance $[4,15]$. With reference to the above studies and project background, we set the total output function for the cooperative cooperation between the general contractor and the subcontractor as $M=\eta e_{c}+\gamma e_{s}+\xi$. The output here refers to the joint efforts of the general contractor and the subcontractor in terms of social responsibility, including project quality improvement, rational use of resources, protection of the ecological environment, etc., where $e_{c}$ and $e_{S}$ are the social responsibility effort levels of the general contractor and subcontractor, $\eta$ and $\gamma(\eta>0, \gamma>0)$ are the coefficients that characterize the influence of the social responsibility efforts of the general contractor and the subcontractor on the output, respectively, $\xi$ is the output when social responsibility is not considered. Since this paper mainly examines the impact of information symmetry and asymmetry of social responsibility on output and revenue, based on not affecting the research and for the convenience of calculation, we set the expectation $E(\xi)=0[36,40]$.

(5) According to references $[37,41], \mathrm{e}^{\rho}$ is the cost of social responsibility, where $k$ is the coefficient of effort cost. Due to the increasing effect of cost and the marginal cost of social responsibility for megaprojects, when $\rho>1$, i.e., $k \mathrm{e}^{\rho}$ is the convex function of $e$, it conforms to the actual process of the social responsibility cost of megaprojects, and $\rho=2$ is the most common situation. Based on this idea, we suppose the effort costs of contractor and subcontractor are $c\left(e_{c}\right)=\frac{1}{2} k_{c} e_{c}^{2}$ and $c\left(e_{s}\right)=\frac{1}{2} k_{s} e_{s}^{2}$, where $k_{c}$ and $k_{s}\left(k_{c}\right.$, $\left.k_{s}>0\right)$ are the social responsibility effort cost coefficients of general contractor and subcontractor, respectively.

The symbols and related descriptions used in this paper are shown in Table 1. 
Table 1. Symbols and related descriptions.

\begin{tabular}{|c|c|}
\hline Symbols & Related Descriptions \\
\hline$W$ & The total contract price signed by the owner (government) and the general contractor \\
\hline $\bar{\omega}$ & $\begin{array}{l}\text { The fixed total price obtained by the general contractor after reaching the lowest quality, construction } \\
\text { period, and cost standards }\end{array}$ \\
\hline$M$ & $\begin{array}{l}\text { The total output obtained from the collaboration of the general contractor and subcontractor in terms of } \\
\text { social responsibility }\end{array}$ \\
\hline$\lambda$ & $\begin{array}{l}\text { The owner's incentive coefficient for the general contractor and subcontractor's contribution to social } \\
\text { responsibility }\end{array}$ \\
\hline$P$ & The total contract price signed by the general contractor and the subcontractor \\
\hline $\bar{p}$ & $\begin{array}{l}\text { The fixed total price obtained by the subcontractor for completing the subcontracted project in } \\
\text { accordance with the minimum requirements }\end{array}$ \\
\hline$\beta$ & The revenue distribution ratio of the general contractor after receiving the owner's reward \\
\hline$e_{c}$ & The social responsibility effort level of the general contractor \\
\hline$e_{S}$ & The social responsibility effort level of the subcontractor \\
\hline$\eta$ & The influence coefficient of the general contractor's social responsibility efforts on the output \\
\hline$\gamma$ & The influence coefficient of the subcontractor's social responsibility efforts on the output \\
\hline$\xi$ & Output when social responsibility is not considered \\
\hline$k_{c}$ & The social responsibility effort cost coefficient of the general contractor \\
\hline$k_{S}$ & The social responsibility effort cost coefficient of the subcontractor \\
\hline $\bar{k}_{S}$ & The upper limit of subcontractor's fixed cost under information asymmetry \\
\hline$\varepsilon$ & The degree of opacity of subcontractor's social responsibility information under asymmetric information \\
\hline
\end{tabular}

\subsection{Single-Stage Revenue-Sharing Model under Information Symmetry}

Under the symmetric social responsibility information, the deterministic revenue function of the general contractor is expressed as

$$
\pi_{c}=\bar{\omega}+\beta \lambda\left(\eta e_{c}+\gamma e_{s}\right)-\bar{p}-\frac{1}{2} k_{c} e_{c}^{2}
$$

The deterministic revenue function of the subcontractor is expressed as

$$
\pi_{s}=\bar{p}+(1-\beta) \lambda\left(\eta e_{c}+\gamma e_{s}\right)-\frac{1}{2} k_{s} e_{s}^{2}
$$

In megaprojects, the general contractor is the leader who has the dominant power. First, we determine the revenue distribution ratio $\beta$ and its effort level $e_{c}$. The subcontractor is the follower, and then we determine its own effort level $e_{s}$ after the general contractor makes a decision. By the backward induction method, the subgame-perfect equilibrium can be obtained.

Equation (2) takes the first-order derivative of $e_{S}$ and we set it to 0 , then

$$
e_{s}=\frac{(1-\beta) \gamma \lambda}{k_{s}}
$$

Substituting Equation (3) into Equation (1), we obtain

$$
\pi_{c}=\bar{\omega}+\beta \lambda\left(\eta e_{c}+\frac{(1-\beta) \lambda \gamma^{2}}{k_{s}}\right)-\bar{p}-\frac{1}{2} k_{c} e_{c}^{2}
$$


For $e_{c}$ and $\beta$, the contractor obtains the Hessian matrix $H^{S}=\left[\begin{array}{cc}\frac{\partial^{2} \pi_{c}}{\partial e_{c}^{2}} & \frac{\partial^{2} \pi_{c}}{\partial e_{c} \partial \beta} \\ \frac{\partial^{2} \pi_{c}}{\partial \beta \partial e_{c}} & \frac{\partial^{2} \pi_{c}}{\partial \beta^{2}}\end{array}\right]=$ $\left[\begin{array}{cc}-k_{c} & \lambda \eta \\ \lambda \eta & -\frac{2 \lambda^{2} \gamma^{2}}{k_{s}}\end{array}\right]$, when $2 k_{c} \gamma^{2}>k_{s} \eta^{2}$, the Hessian matrix is negative definite. The above model has an equilibrium solution. Therefore, the equilibrium solution is expressed as

$$
\begin{gathered}
\beta^{S *}=\frac{k_{c} \gamma^{2}}{2 k_{c} \gamma^{2}-k_{s} \eta^{2}}, e_{c}^{S *}=\frac{\lambda \eta \gamma^{2}}{2 k_{c} \gamma^{2}-k_{s} \eta^{2}}, e_{s}^{S *}=\frac{\lambda \gamma\left(k_{c} \gamma^{2}-k_{s} \eta^{2}\right)}{k_{s}\left(2 k_{c} \gamma^{2}-k_{s} \eta^{2}\right)^{2}}, \\
\pi_{c}^{S *}=\bar{\omega}-\bar{p}+\frac{k_{c} \lambda^{2} \gamma^{4}}{2 k_{s}\left(2 k_{c} \gamma^{2}-k_{s} \eta^{2}\right)} \\
\pi_{s}^{S *}=\bar{p}+\frac{\gamma^{2} \lambda^{2}\left(k_{c} \gamma^{2}-k_{s} \eta^{2}\right)\left(k_{c} \gamma^{2}+k_{s} \eta^{2}\right)}{2 k_{s}\left(2 k_{c} \gamma^{2}-k_{s} \eta^{2}\right)^{2}}
\end{gathered}
$$

To ensure that the effort level and revenue of the general contractor and subcontractor are positive, it can be obtained that $k_{c} \gamma^{2}>k_{s} \eta^{2}$, i.e., $\frac{\gamma^{2}}{k_{s}}>\frac{\eta^{2}}{k_{c}}$, i.e., the input-output factor of the subcontractor is greater than that of the general contractor. This is because megaprojects have high complexity, and the general contractor cannot complete some challenging projects alone. The general contractor will screen outstanding subcontractors in the industry to complete it in collaboration, so $\frac{\gamma^{2}}{k_{s}}>\frac{\eta^{2}}{k_{c}}$ is in line with the actual situation, and subsequent proofs on information symmetry are based on this condition.

Proposition 1. In the single-stage revenue-sharing model with symmetric information, (1) $\frac{\partial e_{c}{ }^{* *}}{\partial k_{c}}<0, \frac{\partial e_{s}{ }^{s *}}{\partial k_{s}}<0 ;(2) \frac{\partial \beta^{S *}}{\partial \eta}>0, \frac{\partial \beta^{S *}}{\partial \gamma}>0 ; \frac{\partial \beta^{S *}}{\partial k_{s}}>0$.

Proposition 1 shows that in a single-stage revenue-sharing model with symmetric information, higher social responsibility cost will inhibit the enthusiasm of general contractors and subcontractors to invest in social responsibility; the revenue distribution ratio $\beta$ has nothing to do with the owner's incentive coefficient, and is related to the effort output coefficient and cost coefficient of the social responsibility of both parties, i.e., it is related to the input-output ratio. The input-output ratio reflects the organization's ability and efficiency to some extent. Therefore, Proposition 1 shows that in a single-stage revenue model with symmetric information, the stronger the ability, the higher the distribution ratio.

\subsection{Single-Stage Revenue-Sharing Model under Information Asymmetry}

In reality, due to the long construction period and high complexity of megaprojects, it is difficult for the general contractor to measure the social responsibilities of the subcontractors in terms of the construction environment, green material use, and employee care. The subcontractors will conceal or falsely report relevant information to obtain higher economic benefits, so there exists serious information asymmetry. It may be assumed that the general contractor lacks complete information on the social responsibility costs of the subcontractors. However, the construction period of megaprojects is long, and the general contractor has a general understanding of the cost of the subcontractor based on experience. References [19,37] set the subcontractor's social responsibility cost coefficient $k_{s}$ to be uniformly distributed, and its distribution function is $F\left(k_{s}\right)$, namely $k_{s} \sim\left[\bar{k}_{s}-\varepsilon, \bar{k}_{s}+\varepsilon\right]$, then the probability density function is $f\left(k_{s}\right)=\frac{1}{2 \varepsilon}, 0<\varepsilon<\bar{k}_{s}$, where $\bar{k}_{S}$ is the upper limit of fixed cost, and $\varepsilon$ represents the degree of opacity of the information. The larger the $\varepsilon$, the less transparent the subcontractor's cost information, and the lower the general contractor's grasp of the subcontractor's information. As the leader, the general contractor will first predict the reaction of the subcontractors, and then decide the distribution ratio and effort level. The following context re-adjusts the situation of information symmetry 
to deal with the situation of asymmetric information. From Equation (4), we know that $\pi_{c}=\bar{\omega}+\beta \lambda\left(\eta e_{c}+\frac{(1-\beta) \lambda \gamma^{2}}{k_{s}}\right)-\bar{p}-\frac{1}{2} k_{c} e_{c}^{2}$, and the expected revenue under uncertain cost information is given by

$$
\begin{aligned}
\pi_{c}^{A}=E\left(\pi_{c}\right) & =\int_{\bar{k}_{s}-\varepsilon}^{\bar{k}_{s}+\varepsilon}\left(\bar{\omega}+\beta \lambda\left(\eta e_{c}+\frac{(1-\beta) \lambda \gamma^{2}}{k_{s}}\right)-\bar{p}-\frac{1}{2} k_{c} e_{c}^{2}\right) f\left(k_{s}\right) d k_{s} \\
& =\bar{\omega}+\beta \lambda \eta e_{c}-\bar{p}-\frac{1}{2} k_{c} e_{c}^{2}+\frac{\beta(1-\beta) \lambda^{2} \gamma^{2}}{2 \varepsilon} \ln \frac{\bar{k}_{s}+\varepsilon}{\bar{k}_{s}-\varepsilon}
\end{aligned}
$$

Let $h(\varepsilon)=\ln \frac{\bar{k}_{s}+\varepsilon}{\bar{k}_{s}-\varepsilon} / \varepsilon$, then

$$
\pi_{c}^{A}=\bar{\omega}+\beta \lambda \eta e_{c}-\bar{p}-\frac{1}{2} k_{c} e_{c}^{2}+\frac{\beta(1-\beta) \lambda^{2} \gamma^{2}}{2} h(\varepsilon)
$$

We perform the second-order partial derivatives of $\beta$ and $e_{c}$, respectively, and obtain the Hessian matrix $H^{A}=\left[\begin{array}{cc}\frac{\partial^{2} \pi_{c}}{\partial e_{c}^{2}} & \frac{\partial^{2} \pi_{c}}{\partial e_{c} \partial \beta} \\ \frac{\partial^{2} \pi_{c}}{\partial \beta \partial e_{c}} & \frac{\partial^{2} \pi_{c}}{\partial \beta^{2}}\end{array}\right]=\left[\begin{array}{cc}-k_{c} & \lambda \eta \\ \lambda \eta & -\lambda^{2} \gamma^{2} h(\varepsilon)\end{array}\right]$. When $h(\varepsilon)>\frac{\eta^{2}}{k_{c} \gamma^{2}}$ is satisfied, $H^{A}$ is negative definite. The equilibrium solution is obtained as

$$
\beta^{A *}=\frac{k_{c} \gamma^{2} \ln \frac{\bar{k}_{s}+\varepsilon}{\bar{k}_{s}-\varepsilon}}{2\left(k_{c} \gamma^{2} \ln \frac{\bar{k}_{s}+\varepsilon}{\bar{k}_{s}-\varepsilon}-\varepsilon \eta^{2}\right)}, e_{c}^{A *}=\frac{\lambda \eta \gamma^{2} \ln \frac{\bar{k}_{s}+\varepsilon}{\bar{k}_{s}-\varepsilon}}{2\left(k_{c} \gamma^{2} \ln \frac{\bar{k}_{s}+\varepsilon}{\bar{k}_{s}-\varepsilon}-\varepsilon \eta^{2}\right)}
$$

Equation (6) is substituted into Equations (2), (3), (5) to obtain

$$
\begin{aligned}
& e_{S}^{A *}=\frac{\lambda \gamma\left(k_{c} \gamma^{2} \ln \frac{\bar{k}_{s}+\varepsilon}{\bar{k}_{s}-\varepsilon}-2 \varepsilon \eta^{2}\right)}{2 k_{s}\left(k_{c} \gamma^{2} \ln \frac{\bar{k}_{s}+\varepsilon}{\bar{k}_{s}-\varepsilon}-\varepsilon \eta^{2}\right)} \\
& \pi_{c}^{A *}=\bar{\omega}-\bar{p}+\frac{\gamma^{4} \lambda^{2}\left(\ln \frac{\bar{k}_{s}+\varepsilon}{\bar{k}_{s}-\varepsilon}\right)^{2} k_{c}}{8 \varepsilon\left(k_{c} \gamma^{2} \ln \frac{\bar{k}_{s}+\varepsilon}{\bar{k}_{s}-\varepsilon}-\varepsilon \eta^{2}\right)} \\
& \pi_{S}^{A *} \\
& =\bar{p}+\frac{\gamma^{2} \lambda^{2}\left(k_{c} \gamma^{2} \ln \frac{\bar{k}_{s}+\varepsilon}{\bar{k}_{s}-\varepsilon}-2 \varepsilon \eta^{2}\right)\left(k_{c} \gamma^{2} \ln \frac{\bar{k}_{s}+\varepsilon}{k_{s}-\varepsilon}-2 \varepsilon \eta^{2}+2 k_{s} \eta^{2} \ln \frac{\bar{k}_{s}+\varepsilon}{\bar{k}_{s}-\varepsilon}\right)}{8 k_{s}\left(k_{c} \gamma^{2} \ln \frac{\bar{k}_{s}+\varepsilon}{\bar{k}_{s}-\varepsilon}-\varepsilon \eta^{2}\right)^{2}}
\end{aligned}
$$

To ensure that the above revenues and effort levels are positive, we obtain $k_{c} \gamma^{2} \ln \frac{\bar{k}_{s}+\varepsilon}{\bar{k}_{s}-\varepsilon}>$ $2 \varepsilon \eta^{2}$, i.e., $h(\varepsilon)>\frac{2 \eta^{2}}{k_{c} \gamma^{2}}$.

Proposition 2. In the single-stage revenue-sharing model with asymmetric information, when $h(\varepsilon)>\frac{2 \eta^{2}}{k_{c} \gamma^{2}}$, we have $\frac{\partial e_{c} A *}{\partial k_{c}}<0, \frac{\partial e_{c} A *}{\partial \varepsilon}<0, \frac{\partial \beta^{A *}}{\partial \varepsilon}<0$.

Proof. When $h(\varepsilon)>\frac{2 \eta^{2}}{k_{c} \gamma^{2}}, \frac{\partial e_{c}^{A *}}{\partial k_{c}}=\frac{-\gamma^{4} \lambda \eta\left(\ln \frac{\bar{k}_{s}+\varepsilon}{\bar{k}_{s}-\varepsilon}\right)^{2}}{2\left(-\varepsilon \eta^{2}+\gamma^{2} \ln \frac{\bar{k}_{s}+\varepsilon}{\bar{k}_{s}-\varepsilon}\right)^{2}}<0$,

Although $\frac{\partial e_{c} A *}{\partial \varepsilon}=\frac{\gamma^{2} \eta^{3} \lambda\left(-2 \bar{k}_{s} \varepsilon+\left(\bar{k}_{s}+\varepsilon\right)\left(\bar{k}_{s}-\varepsilon\right) \ln \frac{\bar{k}_{s}+\varepsilon}{\bar{k}_{S}-\varepsilon}\right)}{2\left(\bar{k}_{s}+\varepsilon\right)\left(\bar{k}_{s}-\varepsilon\right)\left(\varepsilon \eta^{2}-\gamma^{2} k_{c} \ln \frac{\bar{k}_{s}+\varepsilon}{\bar{k}_{S}-\varepsilon}\right)^{2}}$, it is obvious that the denominator is greater than 0 , in the numerator, 
Let $g(\varepsilon)=2 \bar{k}_{s} \varepsilon+\left(\bar{k}_{s}+\varepsilon\right)\left(\bar{k}_{s}-\varepsilon\right) \ln \frac{\bar{k}_{s}+\varepsilon}{\bar{k}_{s}-\varepsilon} g(\varepsilon)=0, \frac{\partial g(\varepsilon)}{\partial \varepsilon}=2 \varepsilon \ln \frac{\bar{k}_{s}+\varepsilon}{\bar{k}_{s}-\varepsilon}>0$, so when $\varepsilon>0$, $g(\varepsilon)>0$, thus $\frac{\partial e_{c}^{A *}}{\partial \varepsilon}<0$. Similarly, $\frac{\partial \beta^{A *}}{\partial \varepsilon}=\frac{\gamma^{2} \eta^{2}\left(-2 \bar{k}_{s} \varepsilon+\left(\bar{k}_{s}+\varepsilon\right)\left(\bar{k}_{s}-\varepsilon\right) \ln \frac{\bar{k}_{s}+\varepsilon}{\bar{k}_{s}-\varepsilon}\right) k_{c}}{2\left(\bar{k}_{s}+\varepsilon\right)\left(\bar{k}_{s}-\varepsilon\right)\left(\varepsilon \eta^{2}-\gamma^{2} k_{c} l n \frac{\bar{k}_{s}+\varepsilon}{\bar{k}_{s}-\varepsilon}\right)^{2}}<0$.

Proposition 2 shows that similar to the single-stage revenue model with symmetric information, in the single-stage revenue-sharing model with asymmetric information, higher costs will also inhibit the enthusiasm of the general contractor to invest in social responsibility. In addition, under the information asymmetry, the effort level and distribution ratio of the general contractor will decrease as the opacity degree of the subcontractor's social responsibility information increases, i.e., the greater the degree of opacity of the subcontractor's information, the more restrained the general contractor's investment in social responsibility investment, the lower the corresponding distribution ratio.

\subsection{Comparative Analysis}

To better compare the single-stage revenue-sharing model in the two situations of symmetric and asymmetric social responsibility information, Table 2 summarizes the equilibrium results.

Table 2. Comparison of the equilibrium results of the single-stage revenue-sharing model under the two situations.

\begin{tabular}{|c|c|c|}
\hline Variable & Parameters of Symmetric Information & Parameters of Asymmetric Information \\
\hline Subcontractor's effort level $e_{S}$ & $\frac{\lambda \gamma\left(k_{c} \gamma^{2}-k_{s} \eta^{2}\right)}{k_{s}\left(2 k_{c} \gamma^{2}-k_{s} \eta^{2}\right)}$ & $\frac{\lambda \gamma\left(k_{c} \gamma^{2} \ln \frac{\bar{k}_{s}+\varepsilon}{\bar{k}_{s}-\varepsilon}-2 \varepsilon \eta^{2}\right)}{2 k_{s}\left(k_{c} \gamma^{2} \ln \frac{\bar{k}_{s}+\varepsilon}{\bar{k}_{s}-\varepsilon}-\varepsilon \eta^{2}\right)}$ \\
\hline General contractor's effort level $e_{c}$ & $\frac{\lambda \eta \gamma^{2}}{2 k_{c} \gamma^{2}-k_{s} \eta^{2}}$ & $\frac{\lambda \eta \gamma^{2} \ln \frac{\bar{k}_{s}+\varepsilon}{\bar{k}_{s} \varepsilon}}{2\left(k_{c} \gamma^{2} \ln \frac{\bar{k}_{s}+\varepsilon}{\bar{k}_{s}-\varepsilon}-\varepsilon \eta^{2}\right)}$ \\
\hline Revenue distribution ratio $\beta$ & $\frac{k_{c} \gamma^{2}}{2 k_{c} \gamma^{2}-k_{s} \eta^{2}}$ & $\frac{k_{c} \gamma^{2} \ln \frac{\bar{k}_{s}+\varepsilon}{\bar{k}_{s}-\varepsilon}}{2\left(k_{c} \gamma^{2} \ln \frac{\bar{k}_{s}+\varepsilon}{\bar{k}_{s}-\varepsilon}-\varepsilon \eta^{2}\right)}$ \\
\hline Subcontractor revenue $\pi_{S}$ & $\bar{p}+\frac{\gamma^{2} \lambda^{2}\left(k_{c} \gamma^{2}-k_{s} \eta^{2}\right)\left(k_{c} \gamma^{2}+k_{s} \eta^{2}\right)}{2 k_{s}\left(2 k_{c} \gamma^{2}-k_{s} \eta^{2}\right)^{2}}$ & $\bar{p}+\frac{\gamma^{2} \lambda^{2}\left(k_{c} \gamma^{2} \ln \frac{\bar{k}_{s}+\varepsilon}{\bar{k}_{s}-\varepsilon}-2 \varepsilon \eta^{2}\right)\left(k_{c} \gamma^{2} \ln \frac{\bar{k}_{s}+\varepsilon}{\bar{k}_{s}-\varepsilon}-2 \varepsilon \eta^{2}+2 k_{s} \eta^{2} \ln \frac{\bar{k}_{s}+\varepsilon}{\bar{k}_{s}-\varepsilon}\right)}{8 k_{s}\left(k_{c} \gamma^{2} \ln \frac{\bar{k}_{s}+\varepsilon}{\bar{k}_{s}-\varepsilon}-\varepsilon \eta^{2}\right)^{2}}$ \\
\hline General contractor revenue $\pi_{c}$ & $\bar{\omega}-\bar{p}+\frac{k_{c} \lambda^{2} \gamma^{4}}{2 k_{s}\left(2 k_{c} \gamma^{2}-k_{s} \eta^{2}\right)}$ & $\bar{\omega}-\bar{p}+\frac{\gamma^{4} \lambda^{2}\left(\ln \frac{\bar{k}_{s}+\varepsilon}{\bar{k}_{s}-\varepsilon}\right)^{2} k_{c}}{8 \varepsilon\left(k_{c} \gamma^{2} \ln \frac{\bar{k}_{s}+\varepsilon}{\bar{k}_{s}-\varepsilon}-\varepsilon \eta^{2}\right)}$ \\
\hline
\end{tabular}

Proposition 3. In the single-stage revenue-sharing model, the revenue difference $\pi_{c}^{S *}-\pi_{c}^{A *}$ of the general contractor under symmetric and asymmetric information satisfies: when $\frac{2 \eta^{2}}{k_{c} \gamma^{2}}<h(\varepsilon)<\frac{2}{k_{s}}$, $\pi_{c}^{S *}-\pi_{c}^{A *}>0 ;$ when $h(\varepsilon)>\frac{2}{k_{s}}, \pi_{c}^{S *}-\pi_{c}^{A *}<0$.

Proof. $\pi_{c}^{S *}-\pi_{c}^{A *}=-\frac{\left.\gamma^{4} \lambda^{2} k_{c}\left(4 \eta^{2} \varepsilon^{2}-4 \varepsilon \gamma^{2} l n \frac{\bar{k}_{s}+\varepsilon}{k_{s}-\varepsilon} k_{c}+2 \gamma^{2}\left(\ln \frac{\bar{k}_{s}+\varepsilon}{k_{s}-\varepsilon}\right)^{2} k_{c} k_{s}\right)-\eta^{2}\left(\ln \frac{\bar{k}_{s}+\varepsilon}{\bar{k}_{s}-\varepsilon}\right)^{2} k_{s}^{2}\right)}{8 \varepsilon\left(k_{c} \gamma^{2} \ln \frac{\bar{k}_{s}+\varepsilon}{\bar{k}_{s}-\varepsilon}-\varepsilon \eta^{2}\right) k_{s}\left(2 k_{c} \gamma^{2}-\eta^{2} k_{s}\right)}$

where the denominator is greater than 0 . For the parenthesis of the numerator, we extract $\frac{1}{\varepsilon^{2}}$ and then express it as $\frac{1}{\varepsilon^{2}}\left(\left(2 k_{c} \gamma^{2} k_{s}-\eta^{2} k_{s}{ }^{2}\right) h(\varepsilon)^{2}-4 \gamma^{2} k_{c} h(\varepsilon)+4 \eta^{2}\right.$. This formula is regarded as a quadratic function of $\mathrm{h}(\varepsilon)$, and its quadratic coefficient $2 k_{c} \gamma^{2} k_{s}-\eta^{2} k_{s}{ }^{2}>0$, while

$$
\Delta=\left(4 \gamma^{2} k_{c}\right)^{2}-4 \times 4 \eta^{2}\left(2 k_{c} \gamma^{2} k_{s}-\eta^{2} k_{s}^{2}\right)=16\left(k_{c} \gamma^{2}-k_{s} \eta^{2}\right)>0
$$

Therefore, when $h(\varepsilon)$ falls between $\frac{2 \eta^{2}}{2 k_{c} \gamma^{2}-k_{s} \eta^{2}}$ and $\frac{2}{k_{s}}$, the numerator satisfies $\left(4 \eta^{2} \varepsilon^{2}-4 \varepsilon \gamma^{2} \ln \frac{\bar{k}_{\bar{s}}+\varepsilon}{\bar{k}_{s}-\varepsilon} k_{c}+2 \gamma^{2}\left(\ln \frac{\bar{s}_{\bar{s}_{s}+\varepsilon}}{\bar{k}_{s}-\varepsilon}\right)^{2} k_{c} k_{s}\right)-\eta^{2}\left(\ln \frac{\bar{k}_{s}+\varepsilon}{\bar{k}_{s}-\varepsilon}\right)^{2} k_{s}{ }^{2}<0$. Moreover, because $h(\varepsilon)>\frac{2 \eta^{2}}{k_{c} \gamma^{2}}$, and $\frac{2 \eta^{2}}{k_{c} \gamma^{2}}>\frac{2 \eta^{2}}{2 k_{c} \gamma^{2}-k_{s} \eta^{2}}$, so when $\frac{2 \eta^{2}}{k_{c} \gamma^{2}}<h(\varepsilon)<\frac{2}{k_{s}}, \pi_{c}^{S *}-\pi_{c}^{A *}>0$. On the contrary, when $h(\varepsilon)>\frac{2}{k_{s}}, \pi_{c}^{S *}-\pi_{c}^{A *}<0$. 
Proposition 4. In the single-stage revenue-sharing model, the subcontractor's revenue difference $\pi_{s}^{A *}-\pi_{s}^{S *}$ under symmetric and asymmetric information satisfies: when $h(\varepsilon)>\frac{2 \eta^{2}}{k_{c} \gamma^{2}}$, $\pi_{s}^{A *}-\pi_{s}^{S *}>0, \frac{\partial\left(\pi_{s}^{A *}-\pi_{s}^{S *}\right)}{\partial \varepsilon}>0$

Proof. when $h(\varepsilon)>\frac{2 \eta^{2}}{k_{c} \gamma^{2}}$

$$
\begin{aligned}
& \pi_{s}^{A *}-\pi_{s}^{S *}=\frac{\gamma^{4} \lambda^{2} \ln \frac{\bar{k}_{s}+\varepsilon}{\bar{k}_{s}-\varepsilon}\left(-2 \bar{k}_{s} \varepsilon+\left(\bar{k}_{s}^{2}-\varepsilon^{2}\right) \ln \frac{\bar{k}_{s}+\varepsilon}{\bar{k}_{s}-\varepsilon}\right) k_{c}\left(2 \varepsilon \eta^{2}-\gamma^{2} \ln \frac{\bar{k}_{s}+\varepsilon}{\bar{k}_{s}-\varepsilon} k_{c}\right)}{8\left(\bar{k}_{s}-\varepsilon\right) \varepsilon^{2}\left(\bar{k}_{s}+\varepsilon\right)\left(\varepsilon \eta^{2}-\gamma^{2} \ln \frac{\bar{k}_{s}+\varepsilon}{\bar{k}_{s}-\varepsilon} k_{c}\right)^{2}}>0 \\
& \frac{\partial\left(\pi_{s}^{A *}-\pi_{s}^{S *}\right)}{\partial \varepsilon}=\frac{\gamma^{2} \eta^{2} \lambda^{2}\left(-2 \bar{k}_{s} \varepsilon+\left(\bar{k}_{s}^{2}-\varepsilon^{2}\right) \ln \frac{\bar{k}_{s}+\varepsilon}{\bar{k}_{s}-\varepsilon}\right)\left(\gamma^{4} k_{c}^{2} \ln {\overline{\bar{k}_{s}}}_{\bar{k}_{s}-\varepsilon}+2 \varepsilon \eta^{4} k_{s}-2 \gamma^{2} \varepsilon \eta^{2} k_{c}\right)}{4\left(\bar{k}_{s}+\varepsilon\right)\left(\bar{k}_{s}-\varepsilon\right)\left(\varepsilon \eta^{2}-\gamma^{2} k_{c} \ln {\overline{k_{s}}}_{\bar{k}_{s}-\varepsilon}\right)^{3} k_{s}}
\end{aligned}
$$

Obviously, when $h(\varepsilon)>\frac{2 \eta^{2}}{k_{c} \gamma^{2}}, \frac{\partial\left(\pi_{s}^{A *}-\pi_{s}^{S *}\right)}{\partial \varepsilon}>0$.

Propositions 3 and 4 explain that: When $\frac{2 \eta^{2}}{k_{c} \gamma^{2}}<h(\varepsilon)<\frac{2}{k_{s}}$, the revenue of the general contractor under information asymmetry is always lower than that under information symmetry. When $h(\varepsilon)>\frac{2}{k_{s}}$, although the revenue of the general contractor under asymmetric information is higher than that under information symmetry, the subcontractor will not negotiate with the general contractor. Because as long as $h(\varepsilon)>\frac{2 \eta^{2}}{k_{c} \gamma^{2}}$, it is always beneficial to the subcontractor. With the increase of opacity degree $\varepsilon$, the subcontractor's revenue difference between under information asymmetry and under information symmetry will become increasingly larger, so the subcontractor will deliberately conceal or falsely report information to obtain greater revenue.

Proposition 5. In the single-stage revenue-sharing model, the total project output under symmetric and asymmetric information satisfies when $\frac{2 \eta^{2}}{k_{c} \gamma^{2}}<h(\varepsilon)<\frac{2}{k_{s}}, M^{S *}>M^{A *}$

Proof. Total output under information symmetry satisfies:

$$
M^{S *}=\eta e_{c}^{S *}+\gamma e_{s}^{S *}=\frac{\gamma^{2} \lambda \gamma^{2} k_{c}}{\left(2 \gamma^{2} k_{c}-k_{s} \eta^{2}\right) k_{S}}
$$

Total output under information asymmetry satisfies:

$$
M^{A *}=\eta e_{s}^{A *}+\gamma e_{c}^{A *}=\frac{\gamma^{2} \lambda\left(-2 \varepsilon \eta^{2}+\ln \frac{\bar{k}_{s}+\varepsilon}{\bar{k}_{s}-\varepsilon}\left(\gamma^{2} k_{c}+\eta^{2} k_{s}\right)\right)}{2\left(\gamma^{2} \ln \frac{\bar{k}_{s}+\varepsilon}{\bar{k}_{s}-\varepsilon} k_{c}-\varepsilon \eta^{2}\right) k_{s}}
$$

when $\frac{2 \eta^{2}}{k_{c} \gamma^{2}}<h(\varepsilon)<\frac{2}{k_{s}}$

$$
M^{S *}-M^{A *}=\frac{\gamma^{2} \eta^{2} \lambda\left(\gamma^{2} k_{c}-\eta^{2} k_{s}\right)\left(2 \varepsilon-\ln \frac{\bar{k}_{s}+\varepsilon}{\bar{k}_{s}-\varepsilon} k_{s}\right)}{2\left(\varepsilon \eta^{2}-\gamma^{2} \ln \frac{\bar{k}_{s}+\varepsilon}{\bar{k}_{s}-\varepsilon} k_{c}\right) k_{s}\left(-2 \gamma^{2} k_{c}+\eta^{2} k_{s}\right)}>0 .
$$

Proposition 5 shows that in the single-stage revenue-sharing model, when $\frac{2 \eta^{2}}{k_{c} \gamma^{2}}<h(\varepsilon)<\frac{2}{k_{s}}$, the revenue of the general contractor and the total output of the project under asymmetric information are both lower than those under information symmetry. Therefore, the general contractor has an incentive to encourage subcontractors to disclose 
the cost information regardless of their own revenue or the total revenue of the project. In the single-stage revenue-sharing model, there is only one negotiation variable $\beta$, so the model's incentive adaptability is poor. Next, a multi-indicator two-stage incentive contract is constructed.

\section{Design of Multi-Indicator Two-Stage Incentive Contract under Asymmetric Information}

To encourage subcontractors to disclose their social responsibility information, a multi-indicator two-stage incentive contract is designed in this section. In addition to the distribution ratio $\beta$, the general contractor sets a fixed subsidy $F$ which encourages the subcontractors to increase social responsibility, improve the overall efficiency of the project, and avoid project risks by coordinating the relationship between the two negotiation variables. It is supposed that the general contractor in the first stage first proposes the distribution ratio $\beta$ and the subsidy $F$, and the subcontractor decides whether to accept it and, if not, then renegotiate, and if so, the subcontractor determines its own social responsibility effort level $e_{s}$. In the second stage, the general contractor determines its own social responsibility effort level $e_{c}$ after knowing the effort level of the subcontractor. Therefore, the two-stage incentive model is constructed as follows:

$$
\begin{gathered}
\pi_{c}^{T I M}=\bar{\omega}+\lambda \beta\left(\eta e_{c}+\gamma e_{s}\right)-\bar{p}-\frac{1}{2} k_{c} e_{c}^{2}-F \\
\pi_{s}^{T I M}=\bar{p}+(1-\beta) \lambda\left(\eta e_{c}+\gamma e_{s}\right)-\frac{1}{2} k_{s} e_{s}^{2}+F \geq \pi_{s}^{A *} \\
e_{s}^{T I M *} \in \underset{e_{s}^{T I M}}{\operatorname{argmax}} \pi_{s}^{T I M *}=\underset{e_{s}^{T I M}}{\operatorname{argmax} \bar{p}}+(1-\beta) \lambda\left(\eta e_{c}+\gamma e_{s}\right)-\frac{1}{2} k_{s} e_{s}^{2}+F
\end{gathered}
$$

where $\pi_{c}^{T I M}$ is the revenue of the general contractor under the two-stage contract, and $\pi_{s}^{T I M}$ is the revenue of the subcontractor under the two-stage contract. Equation (8) shows the subcontractor's participation constraint, which guarantees that in the asymmetrical situation, the subcontractor's revenue under the two-stage contract is not lower than the revenue under the single-stage revenue-sharing. Equation (9) is the incentive compatibility constraint of the subcontractor. According to the backward induction method, the general contractor decides its effort level $e_{c}$ to maximize the revenue. The first-order derivation of its revenue function is performed and is set to 0 , then we obtain

$$
e_{c}^{T I M}=\frac{\lambda \beta \eta}{k_{c}}
$$

Substituting Equation (10) into the subcontractor's revenue formula, we obtain

$$
\pi_{s}^{T I M}=p_{0}+(1-\beta) \lambda\left(\frac{\lambda \beta \eta^{2}}{k_{c}}+\gamma e_{s}\right)-\frac{1}{2} k_{s} e_{s}^{2}
$$

Performing the first-order derivation of the subcontractor's revenue function and setting it to 0 , we obtain

$$
e_{s}^{T I M}=\frac{(1-\beta) \lambda \gamma}{k_{s}}
$$

Substituting Equations (10) and (12) into the revenue $\pi_{s}^{T I M}$ of the subcontractor, we obtain

$$
\pi_{s}^{T I M}=\bar{p}+(1-\beta) \lambda\left(\frac{\lambda \beta \eta^{2}}{k_{c}}+\frac{(1-\beta) \lambda \gamma^{2}}{k_{s}}\right)-\frac{1}{2} \frac{(1-\beta)^{2} \lambda^{2} \gamma^{2}}{k_{s}}+F
$$

Tightening the constraints of Equation (8), we obtain

$$
\bar{p}+(1-\beta) \lambda\left(\frac{\lambda \beta \eta^{2}}{k_{c}}+\frac{(1-\beta) \lambda \gamma^{2}}{k_{s}}\right)-\frac{1}{2} \frac{(1-\beta)^{2} \lambda^{2} \gamma^{2}}{k_{s}}+F
$$




$$
=\bar{p}+\frac{\gamma^{2} \lambda^{2}\left(\gamma^{2} k_{c} \ln \frac{\bar{k}_{s}+\varepsilon}{\bar{k}_{s}-\varepsilon}-2 \varepsilon \eta^{2}\right)\left(\gamma^{2} k_{c} \ln \frac{\bar{k}_{s}+\varepsilon}{\overline{k_{s}-\varepsilon}}-2 \eta^{2} \varepsilon+2 \eta^{2} k_{s} \ln \frac{\overline{k_{s}}+\varepsilon}{\overline{k_{s}}-\varepsilon}\right)}{8 k_{s}\left(\gamma^{2} k_{c} \ln \frac{\bar{k}_{s}+\varepsilon}{\bar{k}_{s}-\varepsilon}-\varepsilon \eta^{2}\right)^{2}}
$$

i.e.,

$$
=\frac{\lambda^{2}\left(2 \beta \varepsilon \eta^{2}+(1-2 \beta) \gamma^{2} \ln \frac{\bar{k}_{s}+\varepsilon}{k_{s}-\varepsilon} k_{c}\right)\left((2 \beta-3) \gamma^{4} l n \frac{\bar{k}_{s}+\varepsilon}{\bar{k}_{s}-\varepsilon} k_{c}^{2}+4(\beta-1) \varepsilon \eta^{4} k_{s}+2 \gamma^{2} \eta^{2} k_{c}\left(-(\beta-2) \varepsilon+(1-2 \beta) \ln \frac{\bar{k}_{s}+\varepsilon}{\bar{k}_{s}-\varepsilon} k_{s}\right)\right)}{8 k_{c}\left(\varepsilon \eta^{2}-\gamma^{2} l n \frac{\bar{k}_{s}+\varepsilon}{k_{s}-\varepsilon} k_{c}\right)^{2} k_{s}}
$$

Substituting Equation (14) into Equation (7), we obtain

$$
\begin{aligned}
E\left(\pi_{c}^{T I M}\right) & =\frac{\bar{\omega}-\bar{p}+\left(\lambda ^ { 2 } \left(\left(3-4 \beta^{2}\right) \gamma^{6} \ln \left(\frac{\bar{k}_{s}+\varepsilon}{\bar{k}_{s}-\varepsilon}\right)^{2} k_{c}^{3}-4(\beta-2) \beta \varepsilon^{2} \eta^{6} k_{s}+2 \gamma^{4} \eta^{2} \ln \frac{\bar{k}_{s}+\varepsilon}{\bar{k}_{s}-\varepsilon} k_{c}^{2}\left(2\left(2 \beta^{2}-1\right) \varepsilon\right.\right.\right.}{8 k_{c}\left(\varepsilon \eta^{2}-\gamma^{2} \ln \frac{\bar{s}_{s}+\varepsilon}{\bar{k}_{s}-\varepsilon} k_{c}\right)^{2} k_{s}} \\
+ & \frac{\left.\left.\left.(-1-2(\beta-2) \beta) \ln \frac{\bar{k}_{s}+\varepsilon}{\bar{k}_{s}-\varepsilon} k_{s}\right)+4 \gamma^{2} \varepsilon \eta^{4} k_{c}\left(-\beta^{2} \varepsilon+(1+2(-2+\beta) \beta) \ln \frac{\bar{k}_{s}+\varepsilon}{\bar{k}_{s}-\varepsilon} k_{s}\right)\right)\right)}{8 k_{c}\left(\varepsilon \eta^{2}-\gamma^{2} \ln \frac{\bar{k}_{s}+\varepsilon}{\bar{k}_{s}-\varepsilon} k_{c}\right)^{2} k_{s}}
\end{aligned}
$$

Equation (15) takes the first-order derivative of $\beta$ and sets it to 0 , then

$$
\beta^{T I M *}=\frac{\eta^{2} k_{s}}{\gamma^{2} k_{c}+\eta^{2} k_{s}}
$$

Substituting Equation (16) into Equations (10), (12), (14) respectively, we obtain

$$
\begin{aligned}
e_{c}^{T I M *} & =\frac{\lambda \eta^{3} k_{s}}{k_{c}\left(\gamma^{2} k_{c}+\eta^{2} k_{s}\right)} \\
e_{s}^{T I M *} & =\frac{\gamma^{3} \lambda k_{c}}{\gamma^{2} k_{c} k_{s}+\eta^{2} k_{s}^{2}}
\end{aligned}
$$

$F^{T I M *}$

$$
=-\frac{\gamma^{2} \lambda^{2}\left(2 \varepsilon \eta^{4} k_{s}+\gamma^{2} l n \frac{\overline{\bar{k}_{s}+\varepsilon}}{\bar{k}_{s}-\varepsilon} k_{c}\left(\gamma^{2} k_{c}-\eta^{2} k_{s}\right)\right)\left(3 \gamma^{4} \ln \frac{\overline{\bar{k}_{s}}+\varepsilon}{\bar{k}_{s}-\varepsilon} k_{c}^{2}+2 \eta^{4} k_{s}\left(\varepsilon+\ln \frac{\bar{k}_{s}+\varepsilon}{\bar{k}_{s}-\varepsilon} k_{s}\right)-\gamma^{2} \eta^{2} k_{c}\left(4 \varepsilon+\ln \frac{\bar{k}_{s}+\varepsilon}{\bar{k}_{s}-\varepsilon} k_{s}\right)\right)}{8\left(\varepsilon \eta^{2}-\gamma^{2} \ln \frac{\bar{k}_{s}+\varepsilon}{\bar{k}_{s}-\varepsilon} k_{c}\right)^{2} k_{s}\left(\gamma^{2} k_{c}+\eta^{2} k_{s}\right)^{2}}
$$

Substituting Equations (17)-(19) into Equations (7) and (13), we obtain

$$
\begin{aligned}
& \pi_{s}^{\text {TIM* }} \\
& =\bar{p}+\frac{\gamma^{2} \lambda^{2}\left(-2 \varepsilon \eta^{2}+\gamma^{2} \ln \frac{\bar{k}_{s}+\varepsilon}{\bar{k}_{s}-\varepsilon} k_{c}\right)\left(\gamma^{2} k_{c} l n \frac{\bar{k}_{s}+\varepsilon}{\bar{k}_{k}-\varepsilon}-2 \eta^{2}\left(\varepsilon-k_{s} l \frac{\bar{k}_{s}+\varepsilon}{\bar{k}_{s}-\varepsilon}\right)\right)}{8\left(\varepsilon \eta^{2}-\gamma^{2} k_{c} l n \frac{\bar{k}_{s}+\varepsilon}{\bar{k}_{s}-\varepsilon}\right)^{2} k_{S}} \\
& \pi_{c}^{\text {TIM* }} \\
& =\bar{\omega}-\bar{p} \\
& +\frac{\lambda^{2}\left(4 \varepsilon^{2} \eta^{8} k_{s}^{2}-4 \gamma^{2} \varepsilon \eta^{2} \ln \frac{\bar{k}_{s}+\varepsilon}{k_{s}-\varepsilon} k_{c}\left(\gamma^{4} k_{c}^{2}+\eta^{4} k_{s}^{2}\right)+\gamma^{4} \ln \left(\frac{\bar{k}_{s}+\varepsilon}{\bar{k}_{s}-\varepsilon}\right)^{2} k_{c}^{2}\left(3 \gamma^{4} k_{c}^{2}+\gamma^{2} \eta^{2} k_{c} k_{s}+2 \eta^{4} k_{s}^{2}\right)\right)}{8 k_{c}\left(\varepsilon \eta^{2}-\gamma^{2} \ln \frac{\bar{k}_{s}+\varepsilon}{\bar{k}_{s}-\varepsilon} k_{c}\right)^{2} k_{s}\left(\gamma^{2} k_{c}+\eta^{2} k_{s}\right)}
\end{aligned}
$$

Proposition 6. when $\frac{2 \eta^{2}}{k_{c} \gamma^{2}}<h(\varepsilon)<\frac{2}{k_{s}}, \pi_{c}^{T I M *}-\pi_{c}^{A *}>0$.

\section{Proof.}

$\pi_{c}^{T I M *}-\pi_{c}^{A *}$

$=\frac{\lambda^{2}\left(-\gamma^{6} k_{c}^{3} k_{s}\left(\gamma^{2} k_{c}+\eta^{2} k_{s}\right) h(\varepsilon)^{3}+\gamma^{4} k_{c}^{2}\left(3 \gamma^{4} k_{c}^{2}+2 \gamma^{2} \eta^{2} k_{c} k_{s}+3 \eta^{4} k_{s}^{2}\right) h(\varepsilon)^{2}-4 \gamma^{2} \eta^{2} k_{c}\left(\gamma^{4} k_{c}^{2}+\eta^{4} k_{s}^{2}\right) h(\varepsilon)+4 \eta^{8} k_{s}^{2}\right)}{8 \varepsilon^{4} k_{c}\left(\varepsilon \eta^{2}-\gamma^{2} l \frac{\bar{k}_{s}+\varepsilon}{\bar{k}_{s}-\varepsilon} k_{c}\right)^{2} k_{s}\left(\gamma^{2} k_{c}+\eta^{2} k_{s}\right)}$ 
where the denominator is greater than 0 . In the numerator, we set $\varphi(h(\varepsilon))=-\gamma^{6} k_{c}^{3} k_{s}\left(\gamma^{2} k_{c}+\eta^{2} k_{s}\right) h(\varepsilon)^{3}+\gamma^{4} k_{c}^{2}\left(3 \gamma^{4} k_{c}^{2}+2 \gamma^{2} \eta^{2} k_{c} k_{s}+3 \eta^{4} k_{s}^{2}\right) h(\varepsilon)^{2}-$ $4 \gamma^{2} \eta^{2} k_{c}\left(\gamma^{4} k_{c}^{2}+\eta^{4} k_{s}^{2}\right) h(\varepsilon)+4 \eta^{8} k_{s}^{2}, \varphi(h(\varepsilon))$ is the cubic function of $h(\varepsilon)$, where the cubic coefficient $-\gamma^{6} k_{c}^{3} k_{s}\left(\gamma^{2} k_{c}+\eta^{2} k_{s}\right)<0, \varphi^{\prime}(h(\varepsilon))=-3 \gamma^{6} k_{c}^{3} k_{s}\left(\gamma^{2} k_{c}+\eta^{2} k_{s}\right) h(\varepsilon)^{2}$ $+2 \gamma^{4} k_{c}^{2}\left(3 \gamma^{4} k_{c}^{2}+2 \gamma^{2} \eta^{2} k_{c} k_{s}+3 \eta^{4} k_{s}^{2}\right) h(\varepsilon)+4 \gamma^{2} \eta^{2} k_{c}\left(\gamma^{4} k_{c}^{2}+\eta^{4} k_{s}^{2}\right)$ is the quadratic function of $h(\varepsilon), \Delta=4 \gamma^{8} k_{c}^{4}\left(9 \gamma^{8} k_{c}^{4}+10 \gamma^{4} \eta^{4} k_{c}^{2} k_{s}^{2}-3 \eta^{8} k_{s}^{4}\right)>0$, and $\varphi\left(\frac{2}{k_{s}}\right)=\frac{4\left(\gamma^{4} k_{c}^{2}-\gamma^{2} \eta^{2} k_{c} k_{s}+\eta^{4} k_{s}^{2}\right)^{2}}{k_{s}^{2}}>$ 0 . It can be seen from the function image of the cubic equation, when $\frac{2 \eta^{2}}{k_{c} \gamma^{2}}<h(\varepsilon)<\frac{2}{k_{s}}$, $\pi_{c}^{T I M *}-\pi_{c}^{A *}>0$.

Proposition 6 shows that under the information asymmetry of social responsibility, the revenue of the general contractor under the multi-indicator two-stage contract is greater than the revenue under the single-stage, and the revenue of the subcontractor is not lower than the revenue of the single stage.

Proposition 7. Compared with the single-stage revenue-sharing model, the social responsibility effort level of the subcontractor under the two-stage incentive contract satisfies: $e_{S}^{T I M *}>$ $e_{S}^{A *}, e_{S}^{T I M *}>e_{S}^{S *}$

Proof.

$$
\begin{gathered}
e_{s}^{T I M *}-e_{s}^{A *}=\frac{\lambda \gamma\left(\gamma^{4} \ln \frac{\bar{k}_{s}+\varepsilon}{\bar{k}_{s}-\varepsilon} k_{c}^{2}+2 \varepsilon \eta^{4} k_{s}-\gamma^{2} \eta^{2} \ln \frac{\bar{k}_{s}+\varepsilon}{\bar{k}_{s}-\varepsilon} k_{c} k_{s}\right)}{2\left(\gamma^{2} \ln \frac{\bar{k}_{s}+\varepsilon}{\bar{k}_{s}-\varepsilon} k_{c}-\varepsilon \eta^{2}\right) k_{s}\left(\gamma^{2} k_{c}+\eta^{2} k_{s}\right)}>0 \\
e_{S}^{S *}-e_{s}^{T I M *}=\frac{\lambda \gamma\left(\gamma^{4} k_{c}^{2}-\gamma^{2} \eta^{2} k_{c} k_{s}+\eta^{4} k_{s}^{2}\right)}{k_{s}\left(-2 \gamma^{2} k_{c}+\eta^{2} k_{s}\right)\left(\gamma^{2} k_{c}+\eta^{2} k_{s}\right)}<0
\end{gathered}
$$

Therefore, when $h(\varepsilon)>\frac{2 \eta^{2}}{k_{c} \gamma^{2}}, e_{S}^{T I M *}>e_{S}^{A *}, e_{S}^{T I M *}>e_{S}^{S *}$.

Proposition 7 shows that the design of a two-stage incentive contract is conducive to promoting the disclosure of information by subcontractors. Compared with the singlestage revenue-sharing model, subcontractors work harder, which greatly improves the level of social responsibility. This further verifies the effectiveness of the proposed two-stage incentive contract.

Proposition 8. Compared with the single-stage revenue-sharing model, the total project output under the two-stage incentive contract satisfies: $M^{T I M *}>M^{A *}, M^{T I M *}>M^{S *}$.

Proof. when $h(\varepsilon)>\frac{2 \eta^{2}}{k_{c} \gamma^{2}}$

$$
\begin{gathered}
M^{T I M *}-M^{A *}=\frac{\lambda\left(\gamma^{2} k_{c}-\eta^{2} k_{s}\right)\left(2 \varepsilon \eta^{4} k_{s}+\gamma^{2} \ln \frac{\bar{k}_{s}+\varepsilon}{\bar{k}_{s}-\varepsilon} k_{c}\left(\gamma^{2} k_{c}-\eta^{2} k_{s}\right)\right)}{2 k_{c}\left(-\varepsilon \eta^{2}+\gamma^{2} \ln \frac{\bar{k}_{s}+\varepsilon}{\bar{k}_{s}-\varepsilon} k_{c}\right) k_{s}\left(\gamma^{2} k_{c}+\eta^{2} k_{s}\right)}>0 \\
M^{T I M *}-M^{S *}=\frac{\lambda\left(\gamma^{2} k_{c}-\eta^{2} k_{s}\right)\left(\gamma^{4} k_{c}^{2}-\gamma^{2} \eta^{2} k_{c} k_{s}+\eta^{4} k_{s}^{2}\right)}{k_{c} k_{s}\left(2 \gamma^{2} k_{c}-\eta^{2} k_{s}\right)\left(\gamma^{2} k_{c}+\eta^{2} k_{s}\right)}>0 .
\end{gathered}
$$

Proposition 8 shows that the total output of the project under the two-stage incentive contract is greater than the total output of the project in the single-stage large-stage revenue-sharing model. The two-stage incentive contract can effectively improve the overall efficiency of the project. 


\section{Numerical Analysis}

To compare the mutual influence of factors such as the revenue, effort level, and the degree of information asymmetry of the general contractor and the subcontractor under the two-stage incentive contract, the following numerical examples are used for demonstration. The previous discussion has verified the parameter changes and interrelationships of the revenue-sharing model under information symmetry and information asymmetry. Therefore, the main numerical analysis here regards the change of the revenue and effort level of the general contractor and subcontractor under the two-stage incentive contract with the cost coefficient, output coefficient, and degree of information asymmetry, as well as compare the revenue and effort level in the three situations.

The fixed total price can be obtained according to the requirements of the contract for cost, quality, and construction period. This parameter does not affect the comparison results and analysis, so the fixed total price of the owner to the general contractor is set as $\bar{\omega}=1$ billion, the fixed total price of the general contractor to the subcontractor is set as $\bar{p}=0.5$ billion [36]. Because of the significant and far-reaching impact of megaprojects, if the efforts of the general contractor and subcontractors bring about breakthroughs in terms of social responsibility such as effective ecological environment protection and advanced technological innovation, the owner is willing to give higher rewards. For example, during the construction of the island tunnel project of the Hong Kong-Zhuhai-Macao Bridge, China Communications Construction Company (CCCC) and its subcontractor team stationed on-site for seven years continuously deepened and adjusted the preliminary design and optimized more than $90 \%$ of the initial design of the island tunnel project. They focused on solving the project's due service problem and achieving longevity and durability. For this reason, the island tunnel project increased the design cost by more than three times when the corresponding cost adjustment was restricted by the general contract [5], so $\lambda$ cannot be too small, and we can set $\lambda=0.8$. To study whether the cost coefficient and contribution weight affect the subcontractor's revenue and the degree of symmetry, we take $\gamma=0.3,0.5,0.6,0.8, \bar{k}_{s}=0.4,0.5,0.6,0.8$ to draw the figures reflecting the relationship between the revenue of the subcontractor and the degree of asymmetry $\varepsilon$. The results are shown in Figures 1 and 2.

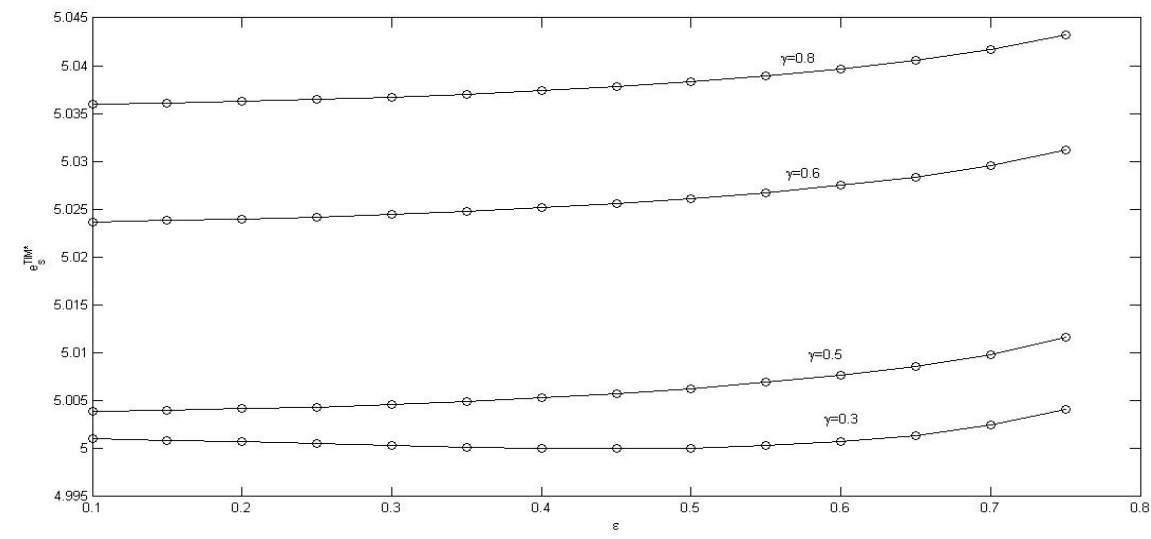

Figure 1. The changing trend of the subcontractor's effort level $e_{s}^{T I M *}$ with $\gamma$ and $\varepsilon$ under the two-stage contract. 


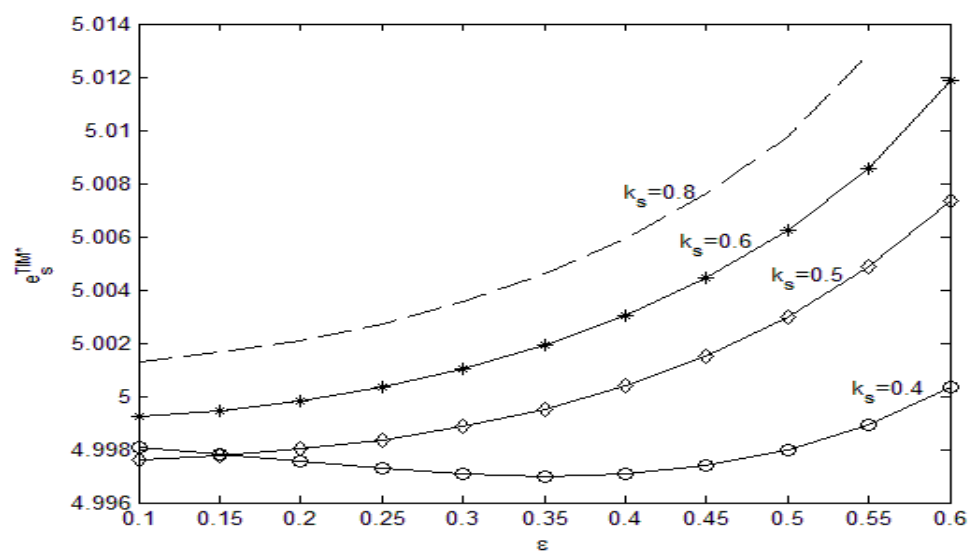

Figure 2. The changing trend of the subcontractor's effort $e_{S}^{T I M *}$ level with $\bar{k}_{S}$ and $\varepsilon$ under the two-stage contract.

Figures 1 and 2 show that under the two-stage incentive contract, the social responsibility effort level of the subcontractor increases with the increase of information asymmetry $\varepsilon$. This changing trend is not related to the social responsibility output coefficient $\gamma$ and social responsibility cost coefficient $\bar{k}_{s}$. At the same time, the larger the subcontractor's output coefficient $\gamma$, the smaller the cost coefficient $\bar{k}_{s}$, the greater the subcontractor's social responsibility effort level. Therefore, the two-stage incentive contract takes into account fairness and efficiency to a certain extent.

The following part analyzes the revenue, social responsibility effort level, and the total output of the project with the degree of information asymmetry $\varepsilon$ of the general contractor and subcontractor under three different models. As far as the cost coefficient and contribution weight of both parties are concerned, when selecting subcontractors, the general contractor must select the most outstanding subcontractor in the industry to collaborate. Therefore, the difference between the input-output ratios $\eta / k_{c}$ and $\gamma / k_{s}$ of the two parties will not be too large. We choose $\gamma=0.6, \eta=0.5, k_{c}=0.75, \bar{k}_{s}=0.8, k_{s}=0.1$ to observe the change trends of the effort level and return of both parties with the degree of asymmetry $\varepsilon$ under the three different models. The results are shown in Figures 3-5.

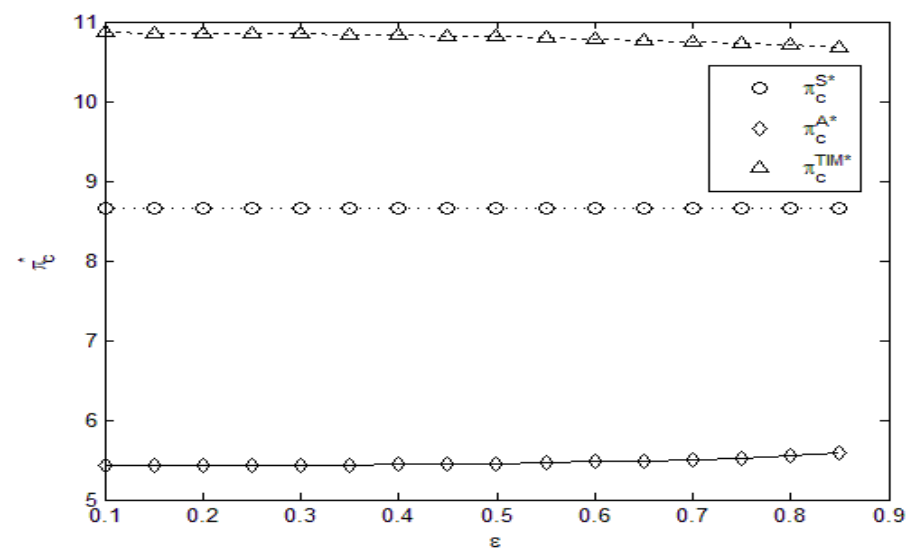

Figure 3. Change trend of general contractor's revenue $\pi_{c}^{*}$ with $\varepsilon$ under the three models. 


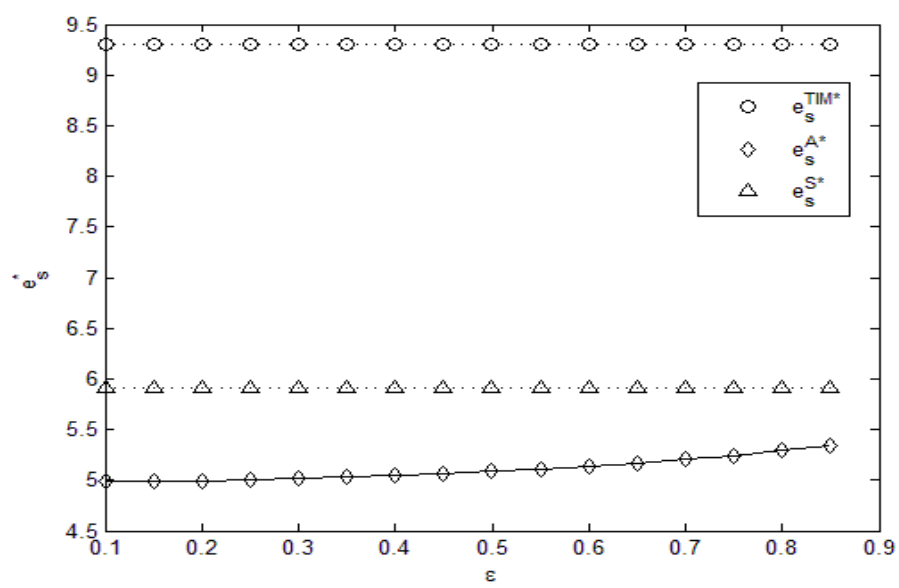

Figure 4. Change trend of subcontractor's effort level $e_{s}^{*}$ with $\varepsilon$ under the three models.

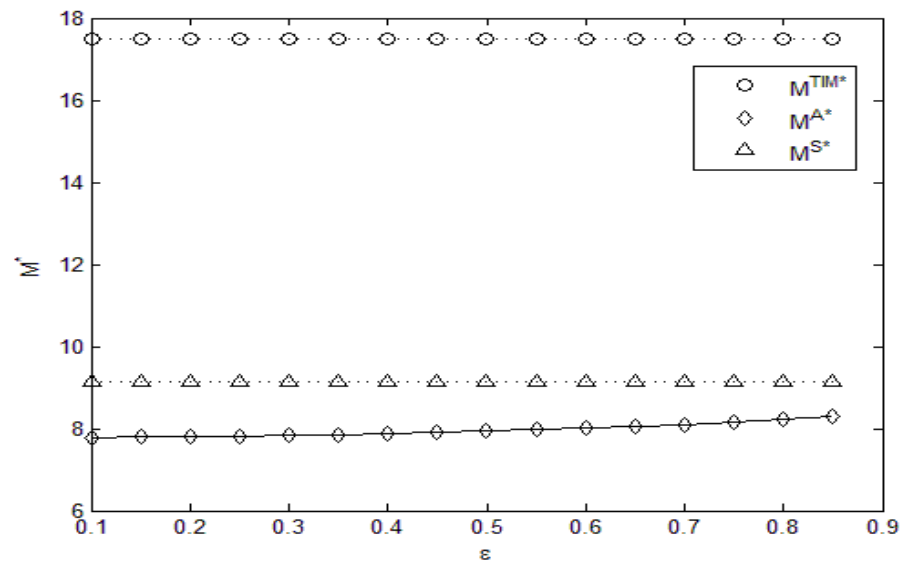

Figure 5. Change trend of total output $M^{*}$ with $\varepsilon$ under the three models.

Figure 3 shows that in the single-stage revenue-sharing model with information asymmetry, the general contractor's revenue increases with the increase in $\varepsilon$. However, it is always lower than the revenue in the single-stage model with information asymmetry, and even lower than the revenue under the two-stage incentive contract. Figure 4 shows that in the two-stage incentive contract, the effort level of the subcontractor is higher than that in the single-stage revenue-sharing model, which further shows that the two-stage incentive contract can promote the subcontractor's social responsibility. Figure 5 shows that under the two-stage incentive contract, the total output of the project is higher than that in the single-stage revenue-sharing model. It further shows that the two-stage incentive contract can improve project efficiency.

\section{Conclusions}

This paper aims at the problem of low engineering efficiency caused by the subcontractor's double information asymmetry behaviors, which are adverse selection and moral hazard. According to the principal-agent theory, this paper combined the characteristics of megaproject social responsibility and the single-stage revenue-sharing model under the situation of information symmetry and information asymmetry. After comparison and analysis, this paper found that subcontractors will deliberately conceal or falsely report social responsibility information to obtain higher profits. Therefore, this paper further designed the multi-index two-stage incentive contract to deal with information asymmetry and quantitatively studied the social responsibility information disclosure mechanism and its impact on the megaproject. The main conclusions are as follows: (1) Regardless of the model, the CSR effort level of general contractors and subcontractors is positively correlated with their contribution weight and the incentive coefficient of owners, but neg- 
atively correlated with the cost coefficient; (2) In the case of information asymmetry, the subcontractor prefers to conceal and exaggerate its social responsibility information, and this behavior will inhibit the enthusiasm of the general contractor to invest in social responsibility. (3) In the single-stage revenue-sharing model, the revenue of the general contractor under information asymmetry is always lower than that under information symmetry, and the profit difference decreases with the degree of subcontractor's information asymmetry. On the contrary, the income of subcontractors under information asymmetry is always higher than that under information symmetry, and the profit difference is increased with the degree of subcontractor's information asymmetry. (4) Compared with the single-stage revenue-sharing model, the revenue of both the contractor and the subcontractor in the two-stage multi-index incentive contract are not lower than those in the single-stage incentive contract, the social responsibility effort level of subcontractor and the total project output are significantly improved.

According to the above conclusions, the following management revelations and suggestions are made:

(1) Establish a social responsibility access mechanism, and strengthen examination and verification of qualification.

The megaprojects have a large investment scale, high construction difficulty, lasting influence, and great significance for the development of the country or region. The owner and general contractor should strengthen the qualification review during the bidding process, give priority to quality and technology, and moderately increase weight indicators such as reputation and social responsibility. In addition, the social responsibility records of subcontractors will be included in the bidding credit rating to ensure that participating organizations have sufficient ability and awareness to fulfill social responsibility, complete project construction, and improve project quality.

(2) Establish an evaluation system for social responsibility and strengthen supervision and management.

The main driving factors of social responsibility behaviors of different participants are different, and in the case of information asymmetry, there is a reverse conduction effect of social responsibility behaviors among participants. Therefore, it requires the owner or the general contractor to establish an operable and quantitative evaluation system of social responsibility and select scientific evaluation indicators, to improve the standardization and efficiency of the megaproject stakeholders' performance of social responsibility. In addition, project managers should constantly strengthen the awareness of social responsibility of subcontractors, strengthen supervision and management of subcontractors, and extend the supervision system from the original standardized operation to the promotion level of social responsibility of project stakeholders, therefore reducing information asymmetry and creating an excellent external environment for engineering construction.

(3) Establish a reasonable incentive mechanism for social responsibility and increase rewards and punishments.

For subcontractors, just as with enterprises, pursuing profit is the fundamental purpose of its business activities. Establishing a reasonable incentive mechanism of social responsibility to achieve the unification of economic interests and social responsibility can promote subcontractors to improve their social responsibility behavior. First, the owner and general contractor can change the "overall rationing system" budget management system, establish the budget management system of "basic cost plus performance reward cost", start from the source of budget management, connect the input of social responsibility with the value of project output, and then improve the effectiveness of incentive. Secondly, they are also supposed to explore the multi-index and staged dynamic incentive mechanism of fixed reward and performance reward, design a scientific and reasonable reward distribution coefficient, to balance the benefit relationship between the project participants and build a benign external environment. Furthermore, to establish a reward and punishment system, clear guidance has been gradually formed to encourage the advanced and spur the 
backward. Owners and contractors can increase rewards and penalties to stimulate project participants to improve social responsibility.

This paper quantitatively studies the social responsibility information disclosure mechanism and influencing factors of megaproject subcontractors, focusing on the design of multi-index and two-stage incentive contracts. The research results provide a theoretical method and decision-making basis for the megaproject general contractors to motivate subcontractors to improve their social responsibility. However, this study still has some shortcomings. First, the study considers the impact of social responsibility on the project output and the benefits of stakeholders, without considering the concerns of fairness among stakeholders, external spillover effects, and social attributes of social responsibility. In the follow-up study, it will become the focus of the research. Secondly, this paper considers the social responsibility incentive mechanism of stakeholders during the construction stage of megaprojects. Further research directions can be extended to the full lifecycle of megaprojects, from point-to-point enterprises to network level. With the help of stochastic game theory and complex network relevant theories, further research on the incentive mechanism of social responsibility of multi-stakeholder in the full lifecycle of megaprojects can be carried out.

Author Contributions: Conceptualization, F.X. and G.C.; methodology, F.X. and G.C.; software, F.X. and G.C.; formal analysis, G.C. and H.X.; investigation, H.X.; resources, G.C.; writing-original draft preparation, F.X. and G.C.; writing-review and editing, G.C. and H.X.; visualization, S.H. and H.X.; supervision, S.H. and H.X.; funding acquisition, S.H. and H.X. All authors have read and agreed to the published version of the manuscript.

Funding: This research was partially funded by the National Natural Science Foundation of China (Grant No. 7153003), the National Natural Science Foundation of China (Grant No. 72101172), the project funded by China Postdoctoral Science Foundation (Grant No. 2021M692375).

Institutional Review Board Statement: No applicable.

Informed Consent Statement: Not applicable.

Data Availability Statement: Not applicable.

Acknowledgments: The authors would like to thank the anonymous reviewers for their criticisms and suggestions.

Conflicts of Interest: The authors declare no conflict of interest.

\section{References}

1. Ma, H.Y.; Zeng, S.X.; Lin, H. The societal governance of megaproject social responsibility. Eur. J. Oper. Res. 2017, 35, 1365-1377. [CrossRef]

2. Brunet, M.; Aubry, M. The three dimensions of a governance framework for major public projects. Int. J. Proj. Manag. 2016, 34, 1596-1607. [CrossRef]

3. Zeng, S.X.; Ma, H.Y.; Lin, H.; Zeng, R.C. Social responsibility of major infrastructure projects in China. Int. J. Proj. Manag. 2015, 33, 537-548. [CrossRef]

4. Ma, H.Y.; Sun, D.X.; Zeng, S.X. The Effects of Megaproject Social Responsibility on Participating Organization. Proj. Manag. J. 2021, 52, 418-433. [CrossRef]

5. Lin, M. Building the World-Class Mega Sea-Crossing: Management Innovation of Hong Kong-Zhuhai-Macao Bridge IslandTunnel Project. J. Manag. World 2017, 12, 1683-1696.

6. Worsnop, T.; Miraglia, S.; Davies, A. Balancing Open and Closed Innovation in Megaprojects: Insights from Cross Rail. Proj. Manag. J. 2016, 47, 79-94. [CrossRef]

7. Ishii, N.; Takano, Y.; Muraki, M. An order acceptance strategy under limited engineering man-hours for cost estimation in Engineering-Procurement-Construction projects. Int. J. Proj. Manag. 2014, 32, 519-528. [CrossRef]

8. Wang, G.; He, Q.H.; Meng, X.H. Exploring the impact of megaproject environmental responsibility on organizational citizenship behaviors for the environment: A social identity perspective. Int. J. Proj. Manag. 2017, 35, 1402-1414. [CrossRef]

9. Xue, L.; Ho, C.M.F.; Shen, G.Q.P. Who should take the responsibility? Stakeholders' power over social responsibility issues in construction projects. J. Clean. Prod. 2017, 154, 318-329.

10. Wang, G.; Wu, P.; Wu, X.Y.; Zuo, J. Mapping global research on sustainability of megaproject management: A scientometric review. J. Clean. Prod. 2020, 259, 120831. [CrossRef] 
11. Lin, H.; Zeng, S.X.; Ma, H.Y. An indicator system for evaluating megaproject social responsibility. Int. J. Proj. Manag. 2017, 35, 1415-1426. [CrossRef]

12. Zhou, Z.P.; Mi, C.M. Social responsibility research within the context of megaproject management: Trends, gaps and opportunities. Int. J. Proj. Manag. 2017, 35, 1378-1390. [CrossRef]

13. Yang, R.J.; Zou, P.X.W. Stakeholder-associated risks and their interactions in complex green building projects: A social network model. Build. Environ. 2014, 73, 208-222. [CrossRef]

14. Osei-Kyei, R.; Chan, A.P.C.; Yu, Y.; Chen, C. Social Responsibility Initiatives for Public-Private Partnership Projects: A Comparative Study between China and Ghana. Sustainability 2019, 5, 1338. [CrossRef]

15. He, Q.H.; Chen, X.Y.; Wang, G. Managing social responsibility for sustainability in megaprojects: An innovation transitions perspective on success. J. Clean. Prod. 2019, 241, 118395. [CrossRef]

16. Damayanti, R.; Hartono, B.; Wijaya, A. Complexity, Leadership, and Megaproject Performance: A Configuration Analysis. J. Ind. Eng. Res. Manag.-JIEM 2021, 14, 570-603. [CrossRef]

17. Cho, S.Y.; Lee, C.; Pfeiffer, R.J. Corporate social responsibility performance and information asymmetry. J. Account. Public Pol. 2013, 32, 71-83. [CrossRef]

18. Sheng, Z.H.; Cheng, S.P.; Li, Q.; Li, J.Q.; Chen, Y.T. “Governance of China” in Decision-making Governance of Megaprojects. J. Manag. World 2020, 6, 202-213.

19. Xiang, P.C.; Huo, X.S.; Shen, L.Y. Research on the phenomenon of asymmetric information in construction projects-The case of China. Int. J. Proj. Manag. 2015, 33, 589-598. [CrossRef]

20. Sun, J.D.; Wang, L.L. The interaction between BIM's promotion and interest game under information asymmetry. J. Ind. Manag. Optim. 2015, 11, 1301-1319. [CrossRef]

21. Xiong, W.; Zhao, X.B.; Wang, H.M. Information Asymmetry in Renegotiation of Public-Private Partnership Projects. J. Comput. Civil. Eng. 2018, 32, 1943-5487. [CrossRef]

22. Holmstrom, B. Moral hazard and observability. Bell. J. Econ. 1979, 10, 74-91. [CrossRef]

23. Kim, S.; Jung, J.Y.; Cho, S.W. Does Information Asymmetry Affect Dividend Policy? Analysis Using Market Microstructure Variables. Sustainability 2021, 13, 3627. [CrossRef]

24. Paez-Perez, D.; Sanchez-Silva, M. A dynamic principal-agent framework for modeling the performance of infrastructure. Eur. J. Oper. Res. 2016, 254, 576-594. [CrossRef]

25. Akerlof, G. The market for lemons: Quality uncertainty and the market mechanism. Q. J. Econ. 1970, 84, 488-500. [CrossRef]

26. Leimgruber, J.; Krebs, G.; Camhy, A.; Muschalla, D. Model-Based Selection of Cost-Effective Low Impact Development Strategies to Control Water Balance. Sustainability 2019, 11, 2440. [CrossRef]

27. Shi, S.S.; Yin, Y.F.; An, Q.X.; Chen, K. Optimal build-operate-transfer road contracts under information asymmetry and uncertainty Transportat. Res. B Meth. 2021, 152, 65-86. [CrossRef]

28. Qi, C.; Lu, H.; Wang, H.W. Management Innovation of Offsite Construction in Megaprojects: Integrated Management and Supplier Development. J. Manag. World 2019, 35, 39-51.

29. Shi, Q.Q.; Zhou, J.B. Incentive Mechanism of Prefabrication in Megaprojects with Reputational Concerns. Sustainability 2018, 10, 1260. [CrossRef]

30. Qiu, Y.M.; Chen, S.P. Governance Model of Major Infrastructure Projects: From a Perspective of Multiple Functions of the Government. J. Sys. Manag. 2018, 27, 129-156.

31. Jeong, E.; Park, G.; Yoo, S.H. Incentive Mechanism for Sustainable Improvement in a Supply Chain. Sustainability 2019, 11, 3508. [CrossRef]

32. Kouvelis, P.; Zhao, W.H. Supply Chain Contract Design Under Financial Constraints and Bankruptcy Costs. Manag. Sci. 2016, 62, 2341-2357. [CrossRef]

33. Ni, D.B.; Li, K.W.; Tang, X.W. Social responsibility allocation in two-echelon supply chains: Insights from wholesale price contracts Eur. J. Oper. Res. 2010, 207, 1269-1279. [CrossRef]

34. Kuiti, M.R.; Ghosh, D.; Basu, P.; Bisi, A. Do cap-and-trade policies drive environmental and social goals in supply chains: Strategic decisions, collaboration, and contract choices. Int. J. Prod. Econ. 2020, 223, 107537. [CrossRef]

35. Phan, D.A.; Vo, T.L.H.; Nguyen, T.L.A. Coordinating contracts for VMI systems under manufacturer-CSR and retailer-marketing efforts. Int Prod. Econ. 2019, 211, 98-118. [CrossRef]

36. Shi, Q.Q.; Zhu, J.B.; Sheng, Z.H. Study on Profit Distribution of Collaboration in Megaproject Supply Chain. Chin. J. Manag. Sci. 2017, 25, 42-51.

37. Ma, P.; Shang, J.; Wang, H.Y. Enhancing corporate social responsibility: Contract design under information asymmetry. Omega 2017, 67, 19-30. [CrossRef]

38. Modak, N.M.; Kazemi, N.; Cárdenas-Barrón, L.E. Investigating structure of a two-echelon closed-loop supply chain using social work donation as a Corporate Social Responsibility practice. Int. J. Prod. Econ. 2019, 207, 19-33. [CrossRef]

39. Raj, A.; Modak, N.M.; Kelly, P. Analysis of a dyadic sustainable supply chain under asymmetric information. Eur. J. Oper. Res. 2021, 289, 582-594. [CrossRef] 
40. Xue, F.; Chen, G.Y.; Xie, H. Incentive contract design for collaborative innovation of megaproject under moral hazard. Sys. Eng. 2021, 39, 49-55.

41. Bhaskaran, S.R.; Krishnan, V. Effort, revenue, and cost sharing mechanisms for collaborative new product development. Manag. Sci. 2009, 55, 1152-1169. [CrossRef] 